\title{
Validation of the Korean Version of the Psychosis Screener to Identify Patients With Psychosis
}

\author{
Hyunsuk Jeong ${ }^{1}$, So Hee Lee², Seung-yup Lee ${ }^{3}$, Jangrae Kim², \\ Gyeongmin Kim¹, Hanseul Kwon', Anna Waterreus ${ }^{4}$, and Hyeon Woo Yim ${ }^{1} \bowtie$ \\ ${ }^{1}$ Department of Preventive Medicine, College of Medicine, The Catholic University of Korea, Seoul, Republic of Korea \\ ${ }^{2}$ Department of Psychiatry, National Medical Center, Seoul, Republic of Korea \\ ${ }^{3}$ Department of Psychiatry, College of Medicine, The Catholic University of Korea, Seoul, Republic of Korea \\ ${ }^{4}$ Neuropsychiatric Epidemiology Research Unit, School of Population and Global Health, The University of Western Australia, Perth, Australia
}

Objective This study aimed to validate the Korean version of a short screening tool for psychosis as the first stage in finding undiagnosed psychosis in the community.

Methods The sample contained 126 consecutive psychiatric outpatients in National Medical Center, Seoul, Korea, between July 20 and July 22, 2020. The Psychosis Screener (PS) comprises 7 items covering psychotic symptoms. The presence of each psychotic symptom was determined by a trained mental health professional and coded "yes" or "no." Two psychiatrists reviewed the medical records independently and extracted the ICD-10-based diagnoses. Any differences between the two clinicians were resolved by consensus, and the agreed diagnosis was used as a gold standard in the study.

Results Among 126 psychiatric outpatients who were enrolled in a consecutive manner during the study period, the proportion of psychosis was $15.1 \%$. The PS showed $78.9 \%$ sensitivity and $72.0 \%$ specificity when the optimal cut-off was 2 , indicating that a score of 2 or more on the screener identified a likely case of psychosis. The area under the curve for the PS was 0.78 (95\% CI: 0.67-0.87).

Conclusion The Korean version of the PS has an ability to discriminate between those who meet the diagnostic criteria for psychosis and those who do not in a high-prevalence group.

Psychiatry Investig 2021;18(8):736-742

Key Words Psychosis, Psychosis screener, Validation, Sensitivity, Specificity, Area under the curve.

\section{INTRODUCTION}

According to a 2016 national epidemiologic study representing the psychiatric community in Korea, the 12-month prevalence of schizophrenia was $0.2 \%{ }^{1}$ This prevalence rate of schizophrenia may be an underestimate, because people who were admitted to hospitals, nursing homes, and special social facilities and households with six or more non-family members were excluded from the survey.

In 2016, the prevalence of schizophrenia was reported to be as high as $0.6 \%$ based on the database of the Health Insurance

Received: December 29, 2020 Revised: April 16, 2021

Accepted: May 30, 2021

$\triangle$ Correspondence: Hyeon Woo Yim, MD, PhD

Department of Preventive Medicine, College of Medicine, The Catholic University of Korea, 222 Banpo-dero, Seocho-gu, Seoul 06591, Republic of Korea Tel: +82-2-2258-7860, Fax: +82-2-532-3820, E-mail: y1693@catholic.ac.kr

(a) This is an Open Access article distributed under the terms of the Creative Commons Attribution Non-Commercial License (https://creativecommons.org/licenses/by$\mathrm{nc} / 4.0$ ) which permits unrestricted non-commercial use, distribution, and reproduction in any medium, provided the original work is properly cited.
Review and Assessment Service (HIRA) in Korea. ${ }^{2}$ Since the HIRA's database of insurance claims data represents the number of patients with schizophrenia currently being treated, it is also possible that this prevalence of schizophrenia is underestimated because patients not yet diagnosed with schizophrenia were not included.

In order to provide the appropriate care and management for people with schizophrenia in the community, it is necessary to accurately estimate a prevalence rate of schizophrenia that considers the magnitude of undiagnosed persons with schizophrenia.

Lengthy interview instruments exist for the assessment of psychotic disorders, but they often require accredited training to administer, and their length means they may not be appropriate for all situations. ${ }^{3}$ Validated screening instruments provide a useful alternative to the full assessment tools for a disorder. ${ }^{4}$ The Psychosis Screener (PS) was developed by researchers as the first stage of screening in the Australian National Survey of Mental Health and Well-Being (NSMHWB) 
Survey of Adults to find undiagnosed cases of psychosis in the community. ${ }^{5}$

The aim of this study was to examine the validity of the Korean-translated version of the PS, compared to full diagnoses of psychotic disorders using the International Classification of Diseases, 10th edition (ICD-10), ${ }^{6}$ in order to provide appropriate management for people with psychosis in the community.

\section{METHODS}

\section{Participants}

The National Medical Center, located in the center of Seoul, is the nation's largest national hospital operated by the Korean government. Compared to general psychiatric hospitals, it is primarily used by people from underprivileged groups who are socially and economically vulnerable. The hospital is a nationally designated center for victims of disasters such as the MERS epidemic and the COVID-19 pandemic and the survivors and family members of victims of the Sewol ferry sinking. The sample contained 126 consecutive psychiatric outpatients in the National Medical Center for whom screener items were completed between July 20 and July 22, 2020. The inclusion criteria were 1) age $\geq 19$ years and 2) ability to communicate in Korean, and the exclusion criteria were 1) mental retardation or 2) comorbid, severe medical or surgical diseases.

\section{Sample size}

We assumed that the PS sensitivity was $82 \%$ and specificity was $57 \%$, based on the results of the previously conducted study in Australia for the NSMHWB Survey. ${ }^{5}$ In a group with a prevalence rate of $20 \%$, the required sample size was 126 in order to estimate a sensitivity of 0.82 and a $95 \%$ confidence interval (CI) width of 0.15 , and a sample size of 118 was required to estimate a specificity of 0.57 and a $95 \%$ CI width of 0.10 . Therefore, the larger sample size of 126 was the target in the estimation of sensitivity and specificity for the current study.

\section{Measurements}

\section{Socio-demographic characteristics}

Socio-demographic characteristics, including age, sex, and status of employment, were recorded.

\section{Psychosis screener}

The Psychosis Screener (PS) uses elements of the Composite International Diagnostic Interview (CIDI) to assess the presence of characteristic psychotic symptoms. The Psychosis Screener comprises 7 items, of which the first 6 cover the fol- lowing features of psychotic disorders: delusional mood, grandiose delusion, delusions of persecution, delusion of reference, delusions of control, and hallucination. Respondents were asked about their ever experiences with psychotic symptoms. The final item records whether a respondent reported ever receiving a diagnosis of schizophrenia. The presence of each psychotic symptom was determined by a trained mental health professional and coded "yes" or "no". Supplementary Materials (in the online-only Data Supplement) showed Korean translated version of psychosis screener.

\section{Process of translation to Korean version of PS}

Before starting the translation process, we received permission from the original developer of the PS to validate the Korean version of the PS. The English-to-Korean translation was performed by a psychiatrist. After the process of instrument translation from English into the Korean language, the consensus version of the Korean translation was confirmed by two psychiatric epidemiologists who checked the contents of the translation while comparing the English and Korean versions. A backwards translation into English was conducted by a bilingual doctoral psychologist.

The original developer assessed the compatibility between the backward translated version and the original instrument in terms of semantic and conceptual equivalence to assess whether the words have the same meaning and whether a given expression had the same connotation in different cultures. By carefully comparing the original version and the backwards translation version of the PS, the final Korean version of PS was obtained for use in the current study.

\section{Procedure of the PS interview}

Before initiation of the survey, a two-hour workshop for training in administration of the PS was provided to two clinical psychologists with at least ten years of experience. The interviewers were blinded to each patient's diagnosis and severity of disease. The average interview time was 7 minutes. At retest, approximately four weeks later, participants in the subpopulation $(n=20)$ also completed the PS.

\section{Clinician diagnosis of psychosis}

Two psychiatrists independently reviewed the medical records and extracted the clinician-rated ICD-10 diagnoses. In case of disagreement, the diagnosis was decided by consensus between the two clinicians. The participants' diagnoses were as follows: schizophrenia, schizoaffective disorder, or schizophrenia spectrum disorder (F20-F29); bipolar disorder (F31); depression (F32-F34); post-traumatic stress disorder (PTSD) (F43); insomnia (F51); and anxiety or panic disorder (F41). The gold standard for psychosis was either schizophrenia, 
schizoaffective disorder, or schizophrenia spectrum disorder (F20-F29). ${ }^{6}$ Participants were classified into the "psychosis" group when they were diagnosed with the aforementioned definition of psychosis and into the "non-psychosis" group when they were diagnosed with other psychiatric diseases.

\section{Statistical analysis}

Demographic and clinical characteristics were summarized using descriptive statistics such as numbers and percentages for categorical variables or means and standard deviations (SDs) for continuous variables. The optimal cut-off point used to distinguish psychosis and non-psychosis diagnosed by the 'gold standard' method in this analysis was defined as that which maximized both the sensitivity and the specificity of the screener. The positive predictive value (PPV) and negative predictive value (NPV) of the cut-off points were also calculated in the psychiatric outpatient clinic. The differences between each PS item in the psychosis and non-psychosis groups were calculated using chi-square analysis. All analyses were conducted using the software packages SAS version 9.4 (SAS Institute Inc., Cary, NC, USA) and MedCalc 12.7.0 (MedCalc Software, Ostend, Belgium).

\section{Ethics approval and consent to participate}

Written consent was acquired from all participants following explanation of the nature of the principles of research, including confidentiality and the freedom of choice to participate. This study received a full review and an approval from the Institutional Review Board of National Medical Center, Seoul, Korea (NMC-2007-029). All procedures were conducted in accordance with the Helsinki Declaration.

\section{RESULTS}

Among the 126 psychiatric outpatients who were enrolled in a consecutive manner during the study period, the prevalence of psychosis was $15.1 \%$. There were no significant differences in age or sex between the psychosis and the non-psychosis groups.

Of the 107 patients classified as non-psychosis, 6 (5.6\%) were diagnosed with bipolar disorder, 55 (51.4\%) with depression, $22(22.9 \%)$ with anxiety or panic disorder, $9(8.4 \%)$ with PTSD, 6 (5.6\%) with insomnia, and 6 (5.6\%) with dependence syndrome. Three patients (3.1\%) were classified as having other conditions such as Alzheimer's disease and alcohol dependence (Table 1).

The internal consistency of the PS in the current study was high (Cronbach's $\alpha=0.81 ; 95 \%$ CI 0.65-0.91). Test-retest reliability was fair ( $r=0.69)$. At retest, the participants rated their psychotic symptoms as slightly more severe than at the initial test, but the difference was not statistically significant. Compared to the non-psychosis group, patients diagnosed with psychosis reported experiencing more delusions and hallucination. Among the psychosis cases, $63.2 \%$ reported experiencing hallucination, and the proportion that reported experiencing symptoms was $57.9 \%$ for both delusional mood and delusions of persecution (Figure 1).

The screener showed $78.9 \%$ sensitivity and $72.0 \%$ specificity when the optimal cut-off was 2 , indicating that a score of 2 or more on the screener identified a likely case of psychosis. The area under the curve (AUC) for the PS was 0.78 (95\% CI: $0.67-0.89$ ). The positive predictive value was $33.3 \%$, and the negative predictive value was $95.1 \%$ in an outpatient psychiatric clinic (Figure 2, Table 2).

Forty-three participants showed an inconsistency between the PS test results and the clinical diagnosis. Of these, 3 were false negative, and 40 were false positive. All three false negatives were female. Among the 40 false positives, 5 were diagnosed with bipolar disorder, 4 with PTSD, 24 with depression, 4 with anxiety or panic disorder, one with insomnia, and 2

Table 1. Demographic characteristics of patients $(\mathrm{N}=126)$

\begin{tabular}{|c|c|c|c|}
\hline Variables & $\begin{array}{c}\text { Psychosis } \\
(\mathrm{N}=19)\end{array}$ & $\begin{array}{l}\text { Non-psychosis } \\
\quad(\mathrm{N}=107)\end{array}$ & $\mathrm{p}$ value \\
\hline Age (years) & & & 0.161 \\
\hline $19-64$ & $17(89.5)$ & $80(74.8)$ & \\
\hline$\geq 65$ & $2(10.5)$ & $27(25.2)$ & \\
\hline Sex & & & 0.307 \\
\hline Male & $7(36.8)$ & $53(49.5)$ & \\
\hline Female & $12(63.2)$ & $54(50.5)$ & \\
\hline Employed & & & 0.092 \\
\hline Yes & $2(10.5)$ & $31(29.0)$ & \\
\hline No & $17(89.5)$ & $76(71.0)$ & \\
\hline \multicolumn{4}{|c|}{ Clinician rated ICD-10 diagnosis } \\
\hline $\begin{array}{l}\text { Schizophrenia, } \\
\text { schizoaffective }\end{array}$ & $19(100)$ & - & \\
\hline Bipolar disorder & - & $6(5.6)$ & \\
\hline Depression & - & $55(51.4)$ & \\
\hline $\begin{array}{l}\text { Anxiety or } \\
\text { Panic disorder }\end{array}$ & - & $22(22.9)$ & \\
\hline PTSD & & $9(8.4)$ & \\
\hline Insomnia & - & $6(5.6)$ & \\
\hline $\begin{array}{l}\text { Dependence } \\
\text { syndrome }\end{array}$ & - & $6(5.6)$ & \\
\hline Other & - & $3(2.8)$ & - \\
\hline
\end{tabular}

$\mathrm{p}$ values for age and sex were calculated by chi-square test, the $\mathrm{p}$ value for employment was calculated by Fisher's exact test, and the $p$ value for psychosis symptoms was calculated by t-test. ICD-10: International Classification of Diseases, Tenth Revision, PTSD: posttraumatic stress disorder 


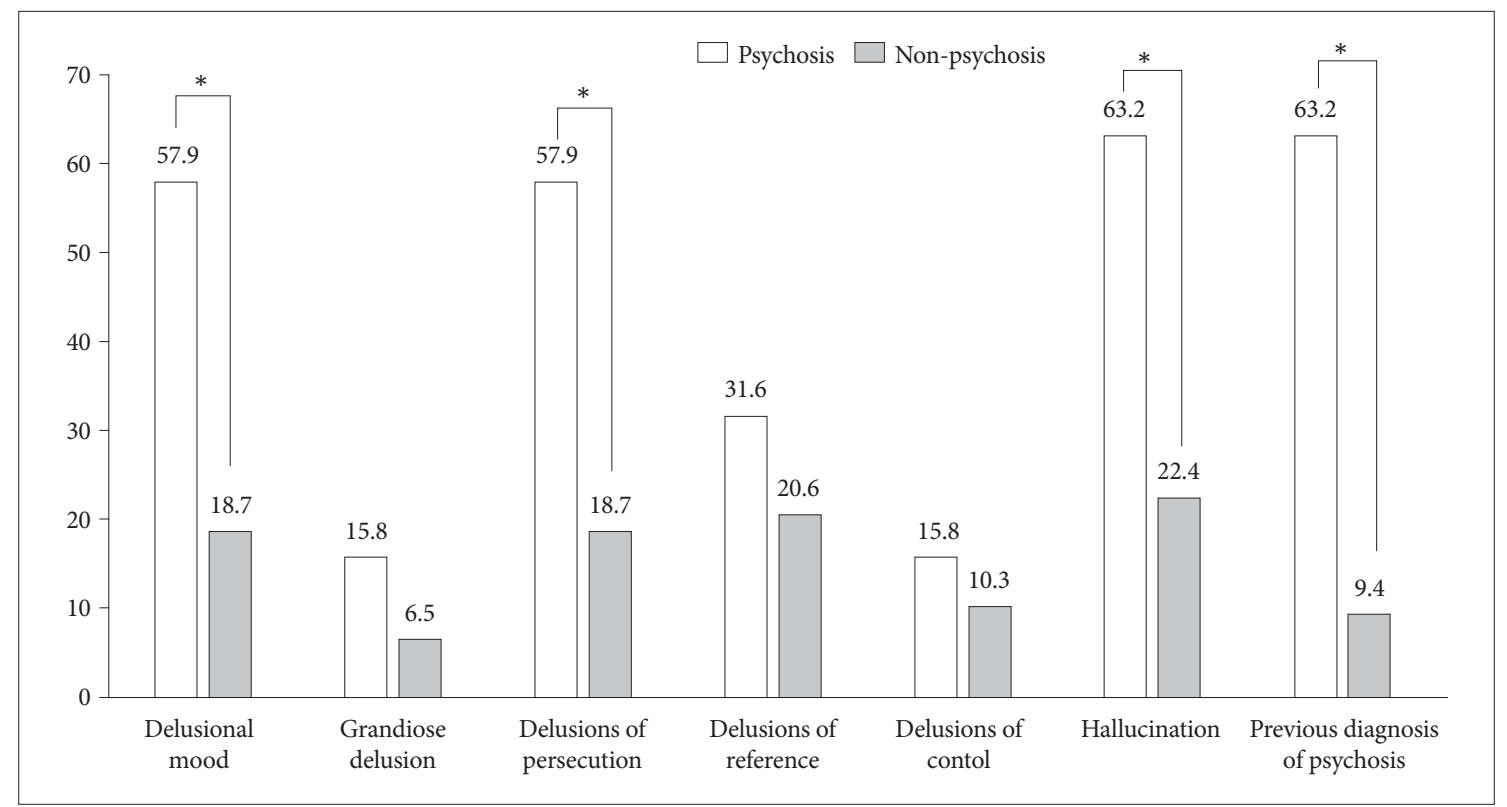

Figure 1. The proportion of each psychosis symptom in the groups with and without psychosis diagnosis. ${ }^{*} p<0.001$.

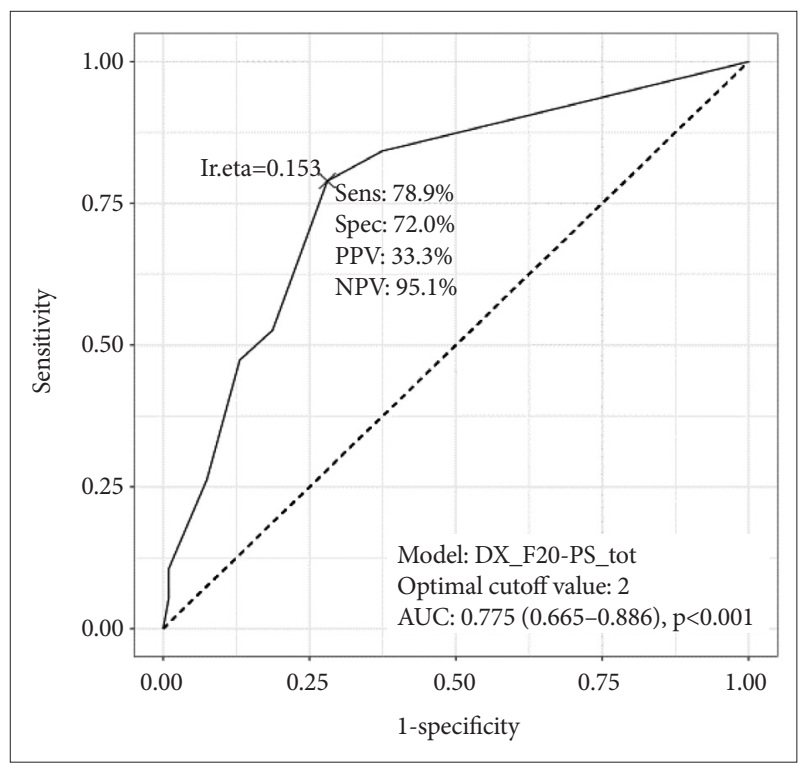

Figure 2. Receiver operating characteristic curve of the Psychosis Screener scores for predicting a diagnosis of psychosis (ICD-10 codes: F20-F29) among psychiatric patients. PPV: positive predictive value, NPV: negative predictive value, AUC: area under the curve.

with dependence syndrome. Most of the false positive patients were adults aged $19-64$, and only $12.5 \%$ were aged 65 or older (Table 3).

\section{DISCUSSION}

This study was conducted to validate the Korean version of a short screening instrument designed for the detection of psychosis. The participants were enrolled at a psychiatric out-
Table 2. Sensitivities, specificities, positive predictive values, and negative predictive values of the psychosis screener at various cut points

\begin{tabular}{ccccc}
\hline Cut off & Sensitivity & Specificity & PPV & NPV \\
\hline$\geq 0$ & 100 & 0 & 15.1 & 100 \\
$\geq 1$ & 84.2 & 62.6 & 28.6 & 95.7 \\
$\geq 2$ & 78.9 & 72.0 & 33.4 & 95.1 \\
$\geq 3$ & 52.6 & 81.3 & 33.3 & 90.6 \\
$\geq 4$ & 47.4 & 86.9 & 39.2 & 90.3 \\
$\geq 5$ & 26.3 & 92.5 & 38.4 & 87.6 \\
$\geq 6$ & 10.5 & 99.1 & 67.5 & 86.2 \\
$\geq 7$ & 5.3 & 99.1 & 51.2 & 85.5 \\
\hline
\end{tabular}

PPV: positive predictive value, NPV: negative predictive value

patient clinic in a consecutive manner during the study period to avoid selection bias. The prevalence of psychosis (F20-F29) in the current study was $15.1 \%$. The proportion of schizophrenia patients among psychiatric outpatients in general hospitals is known to be around 5\%. The clinics that participated in the current study were hospitals operated by the government with medical expenses for low-income families; therefore, the rate of schizophrenia in this outpatient clinic was relatively high.

The gold standard of psychosis was independently decided by two psychiatrists, one diagnosed after direct examination of the patient, and the other made a diagnosis based on a review of the patient's medical chart. The final diagnoses obtained from the two methods were compared, and if there was any discrepancy, the two psychiatrists came to a consensus.

Since the PS test was independently administered and recorded by a clinical psychologist who did not know the pa- 
Table 3. Characteristics of the 43 patients with discordant results between the Psychosis Screener and the clinician's diagnosis of psychosis

\begin{tabular}{lcc}
\hline \multicolumn{1}{c}{ Characteristics } & $\begin{array}{c}\text { False negative } \\
(\mathrm{N}=3)\end{array}$ & $\begin{array}{c}\text { False positive } \\
(\mathrm{N}=40)\end{array}$ \\
\hline $\begin{array}{l}\text { Age (years) } \\
19-64\end{array}$ & $\begin{array}{c}1(33.3) \\
2(66.7)\end{array}$ & $35(87.5)$ \\
$\geq 65$ & & \\
Sex & 0 & $18(45.0)$ \\
Male & $3(100)$ & $22(55.0)$ \\
Female & & \\
Clinician rated ICD-10 diagnosis & $3(100)$ & \\
Schizophrenia, schizoaffective & & $5(12.5)$ \\
Bipolar disorder & & $4(10.0)$ \\
PTSD & & $24(60.0)$ \\
Depression & & $4(10.0)$ \\
Anxiety, panic & & $1(2.5)$ \\
Insomnia & & $2(5.0)$ \\
Dependence syndrome & & 0 \\
Other & & \\
\hline
\end{tabular}

ICD-10: International Classification of Diseases, Tenth Revision, PTSD: post-traumatic stress disorder

tient's diagnosis, the possibility of information bias might be minimal. The retest of the PS was conducted 4 weeks after the initial evaluation to prevent learning effects from taking the initial test from affecting the retest results.

The sensitivity and specificity of the PS test for the diagnosis of psychosis in an outpatient psychiatric clinic were 78.9\% and $72.0 \%$, respectively, and the reliability of the diagnosis of psychosis was 0.69 . The PS is a simple screening tool measuring hallucination or delusions, which are the representative symptoms of psychosis. The PS is designed to allow mental health professionals to perform face-to-face interviews with patients and to additionally identify symptoms through nonverbal cues such as the facial expressions and gestures of patients during interviews. Nevertheless, three patients with schizophrenia responded that they had no symptoms of delusions or hallucinations, resulting in a false negative rate of $15.8 \%$. All three people who classified as false negatives were women. Since PS is a screening tool that checks schizophrenia symptoms such as delusions and hallucinations in a relatively short time, it does not include probing questions that can sufficiently confirm the history of schizophrenia. Currently, there is a possibility that a false negative may appear in patients who have sufficiently improved or disappeared hallucinations or delusional symptoms at the time of interview. Among them, there is a symptom of schizophrenia, but in the case of one delusion without hallucinations or vice versa, it is possible that they did not satisfy the cut off 2 or more points. Lack of awareness of being ill is present in up to $40 \%-50 \%$ of those with untreated schizophrenia. ${ }^{7}$ Especially, it has been reported that patients with schizophrenia frequently do not recognize the name of schizophrenia due to their stigma in Korea. ${ }^{8}$

When applying this tool, there is a possibility of a false negative result due to potential patient denial of their psychotic symptoms, so even if the patient does not report it directly, it is recommended that the patient be interviewed by a mental health professional who can catch any delusional or hallucinatory characteristics of the patient and ask specific questions to confirm psychotic symptoms. If the interviewer has already established a rapport with the patient, the sensitivity of the screening test might be increased. ${ }^{9}$

The false positive rate of the PS was $28 \%$ in the current study. Almost two-thirds of the false positives were patients with depression. The reason might be due to the fact that depression can be accompanied by psychotic features. Of the depression patients, $19 \%$ had a diagnosis of depression with psychotic features. Psychotic depression is a major depressive episode that is accompanied by psychotic symptoms. ${ }^{10}$ It can be difficult to distinguish from schizoaffective disorder in screening tests that evaluate only the presence or absence of symptoms.

Of the false positives, $12.5 \%$ were patients with bipolar disorder. They are more likely to have hallucinations if they experience severe changes in mood. PTSD accounted for 10\% of false positives. For individuals with PTSD, hearing voices was correlated with dissociative experiences. Although, if present, hallucinations and delusions in PTSD patients tend to be more paranoid and persecutory in nature compared with those observed in patients with primary psychotic disorders, which are more bizarre. ${ }^{11} \mathrm{PS}$ is a screening tool that evaluates only the presence or absence of hallucinations and delusions and does not include a differential diagnosis process. There were many false positives in the diagnosis that would require a differential diagnosis process by a psychiatrist.

The PS showed $78.9 \%$ sensitivity and $72.0 \%$ specificity. When this screening tool was applied to a group of prisoners with a prevalence of psychosis of $10 \%{ }^{12}$ the PPV was $24 \%$. This means that 24 out of 100 positives resulting from the PS screening would be actual cases of psychosis. When this screening tool was applied to homeless people with a prevalence of psychosis of $20 \%,{ }^{13}$ the PPV was $41 \%$. This means that 41 out of 100 positives resulting from the PS screening would be actual cases of psychosis. When considering the PPV, effective screening for early examination of psychosis seems to be possible only in groups with high prevalence.

In psychosis screening, the favorable PPV recorded in a high-prevalence clinical population will fall sharply when the same screening tool is used in the low-prevalence context of 
the general population. Therefore, if someone wants to estimate the prevalence of psychosis in a community setting, screening could be assessed using a two-stage method. The PS might be used as an initial brief screen in which participants can report psychotic symptoms; all screen positives would then be administered the diagnostic interview for clinical assessment of psychosis. The second stage will identify false positives with a random selection of screen negatives that is essential in identifying false negatives. First-stage screening assessments are rarely perfectly sensitive. If the proportion of false positives is substantially large, the burden of administering a two-stage diagnostic interview will be increased. ${ }^{14}$

The PS can also be applied to find those undiagnosed with severe mental illness with a broad definition of psychosis in the community setting. The definition of severe mental illness was a diagnosis of either schizophrenia, schizoaffective disorder, schizophrenia spectrum disorder (F20-F29); affective psychosis such as bipolar disorder (F31); and recurrent depressive disorder (F33). ${ }^{15}$ The PS was well able to discriminate between cases and non-cases using the clinician-diagnosed ICD-10 code as the standard. A score of 1 or more on the PS was the optimal score for severe mental illness. The sensitivity and specificity at this cut-off were $83.9 \%$ and $68.4 \%$, respectively (Supplementary Figure 1 in the online-only Data Supplement).

We have to mentioned several limitations of the study. Firstly, the PS is a tool developed for the purpose of screening people with severe mental illness in the community, however it has been validated for patients in psychiatric hospitals because the prevalence of people with severe mental illness is very low in the community. Secondly, we did not include various psychopathological measures such as, the Brief Psychiatric Rating Scale (BPRS) and the Positive and Negative Syndrome Scale (PANSS) which are widely utilized in schizophrenia researches in the current study. Finally, the PS was not compared with other screening tools in terms of psychometric properties.

Estimation of severe mental illness prevalence was conducted in Australia using the two-phase survey strategies employed in both governmental and non-governmental mental facilities in 2010 using the PS. This involves the use of a brief and easy-to-administer screening instrument in the first phase. The second phase interviews are enriched with those more likely to meet diagnostic criteria. They estimated the prevalence of severe mental illness in the community by applying sampling weights derived from phase 1 to phase 2 data through a process known as Horvitz-Thompson inverse probability weighting. ${ }^{16}$

In our sample, the prevalence of psychotic disorders was considerably higher than would be expected in a community setting. Hence, the sensitivity of the test in the community setting would be lower than that obtained in the current results, while the specificity would be higher.

This is the first study conducted on the Korean version of the PS. The instrument proved to be brief to administer (5-7 minutes) and have an ability to screen psychotic symptoms in an outpatient psychiatric clinic. The PS can be used as a screening tool to detect undiagnosed psychosis in a population with a high prevalence of psychosis, and it also might be used as a tool to accurately estimate the prevalence of people with psychosis or severe mental illness in the community.

\section{Supplementary Materials}

The online-only Data Supplement is available with this article at https://doi.org/10.30773/pi.2020.0456.

\section{Availability of Data and Material}

The datasets generated and/or analyzed during the current study are available from the corresponding author.

\section{Conflicts of Interest}

The authors have no potential conflicts of interest to disclose.

\section{Author Contributions}

Conceptualization: Hyunsuk Jeong, Hyeon Woo Yim, Seung-yup Lee, Anna Waterreus. Data curation: Hyunsuk Jeong, So Hee Lee, Jangrae Kim, Gyeongmin Kim, Hanseul Kwon. Formal analysis: Hyunsuk Jeong, Hyeon Woo Yim. Investigation: Hyunsuk Jeong, Hyeon Woo Yim, So Hee Lee, Seung-yup Lee, Gyeongmin Kim, Hanseul Kwon. Methodology: Hyunsuk Jeong, Hyeon Woo Yim. Project administration: Hyunsuk Jeong, Hyeon Woo Yim, Seung-yup Lee, Anna Waterreu. Writing_original draft: Hyunsuk Jeong, Hyeon Woo Yim. Writing_-review \& editing: all authors.

\section{ORCID iDs}

Hyunsuk Jeong https://orcid.org/0000-0001-5274-3816

So Hee Lee https://orcid.org/0000-0002-9005-3207

Seung-yup Lee https://orcid.org/0000-0001-5635-8958

Jangrae Kim https://orcid.org/0000-0003-3161-7436

Gyeongmin Kim https://orcid.org/0000-0003-2944-8063

Hanseul Kwon https://orcid.org/0000-0002-4337-1210

Anna Waterreus https://orcid.org/0000-0002-1648-7701

Hyeon Woo Yim https://orcid.org/0000-0002-3646-8161

\section{Funding Statement}

This research was supported by a grant of the Korea Mental Health R\&D Project, funded by the Ministry of Health \& Welfare, Republic of Korea (grant number: HL19C0049).

\section{REFERENCES}

1. Hong JP, Lee DW, Hahm BJ, Lee SH, Sung SJ, Youn T, et al. The Survey of Mental Disorders in Korea. Seoul: Ministry of Health and Welfare; 2016.

2. Cho SJ, Kim J, Kang YJ, Lee SY, Seo HY, Park JE, et al. Annual prevalence and incidence of schizophrenia and similar psychotic disorders in the Republic of Korea: a National Health Insurance data-based study. Psychiatry Investig 2020;17:61-70.

3. Seiler N, Nguyen T, Yung A, O’Donoghue B. Terminology and assessment tools of psychosis: a systematic narrative review. Psychiatry Clin Neurosci 2020;74:226-246.

4. Beidas RS, Stewart RE, Walsh L, Lucas S, Downey MM, Jackson K, et al. Free, brief, and validated: standardized instruments for low-resource mental health settings. Cogn Behav Pract 2015;22:5-19. 
5. Morgan VA, Waterreus A, Jablensky A, Mackinnon A, McGrath JJ, Carr V, et al. People living with psychotic illness in 2010: the second Australian national survey of psychosis. Aust N Z J Psychiatry 2012;46:735752.

6. International Statistical Classification of Diseases and Related Health Problems. 10th Revision. Geneva: World Health Organization; 2010.

7. van der Meer L, de Vos AE, Stiekema AP, Pijnenborg GH, van Tol MJ, Nolen WA, et al. Insight in schizophrenia: involvement of self-reflection networks? Schizophr Bull 2013;39:1288-1295.

8. Jang J, Kim S, Lee Y, Kim S, Bae K, Kim J, et al. Attitude toward antipsychotic treatment according to patients' awareness of the name of their illness in patients with schizophrenia. Korean J Schizophr Res 2012;15: 106-113.

9. Miller C. Interviewing Strategies, Rapport, and Empathy (4th ed). In: Segal DL, Harsen M, Editors. Diagnostic Interviewing. New York: Springer, 2019, p.29-53.

10. Ohayon MM, Schatzberg AF. Prevalence of depressive episodes with psychotic features in the general population. Am J Psychiatry 2002;159: 1855-1861.
11. Compean E, Hamner M. Posttraumatic stress disorder with secondary psychotic features (PTSD-SP): diagnostic and treatment challenges. Prog Neuropsychopharmacol Biol Psychiatry 2019;88:265-275.

12. Baranyi G, Scholl C, Fazel S, Patel V, Priebe S, Mundt AP. Severe mental illness and substance use disorders in prisoners in low-income and middle-income countries: a systematic review and meta-analysis of prevalence studies. Lancet Glob Health 2019;7:e461-e471.

13. Ayano G, Tesfaw G, Shumet S. The prevalence of schizophrenia and other psychotic disorders among homeless people: a systematic review and meta-analysis. BMC Psychiatry 2019;19:370.

14. Petticrew MP, Sowden AJ, Lister-Sharp D, Wright K. False-negative results in screening programmes: systematic review of impact and implications. Health Technol Assess 2000;4:1-120.

15. Morgan VA, Waterreus A, Jablensky A, Mackinnon A, McGrath JJ, Carr V, et al. People living with psychotic illness in 2010: the second Australian national survey of psychosis. Aust N Z J Psychiatry 2012;46:735-752.

16. Alonzo TA, Pepe MS, Lumley T. Estimating disease prevalence in twophase studies. Biostatistics 2003;4:313-326. 


\section{Supplementary Materials \\ Korean Translated Psychosis screener}

\section{한국어 버전 Psychosis screener}

1. 망상적 느낌

뭔가 이상하고 설명하기 힘든 것을 느꼈는데 다른 사람들이 믿기 힘들어한 경험을 한번이라도 한적이 있나요?

ㅁ (1) 예

ㅁ (2) 아니오

2. 과대망상

다른 사람들에겐 없고 누구도 가지지 못한 특별한 힘이나 재능을 가졌다고 생각한 적이 있나요?
ㅁ (1) 예
ㅁ (2) 아니오

3. 피해망상

사람들이 당신에게 너무 관심을 갖는 다거나, 나만 콕 집어서 대하거나, 의도적으로 해치려고 시도한다고 느낀 적이 있나요?
ㅁ (1) 예
(2) 아니오

4. 관계망상

당신에게만 특별한 의미 또는 메시지를 전달하기 위해서 물건들이 배열되어 있거나, 사건들이 일어나거나, 이야기를 하는 것으로 느꼈던 적이 한번이라도 있나요?
ㅁ (1) 예
ㅁ (2) 아니오

5. 조종망상; 사고방해; 수동성

텔레파시와 같이 사람들이 잘 믿기 힘들어할 방법으로 당신의 생각이 다른 사람에 의하여 직접적으로 방해되거나 조종 된다고 느낀 적이 한번이라도 있나요?
ㅁ (1) 예
$\square$ (2) 아니오

6. 환각

주변에 아무도 없는데 목소리나 소리가 들리는 잘 설명되어질 수 없는(상식적으로는 설명불가능한) 경험을 한 적이 있나요? 아니면 다른 사람들에게 보이지 않는 게 보였던 적이 있습니까?
ㅁ (1) 예
$\square$ (2) 아니오

7. 조현병, 조현정동장애, 또는 조울증 진단력

당신이 조현병(정신분열증), 조현정동장애(정신분열정동장애)이 있다거나 조울증 또는 양극성장애 일 수 있다고 의사 로부터 진단을 들은 적이 있습니까?
ㅁ (1) 예
ㅁ (2) 아니오 


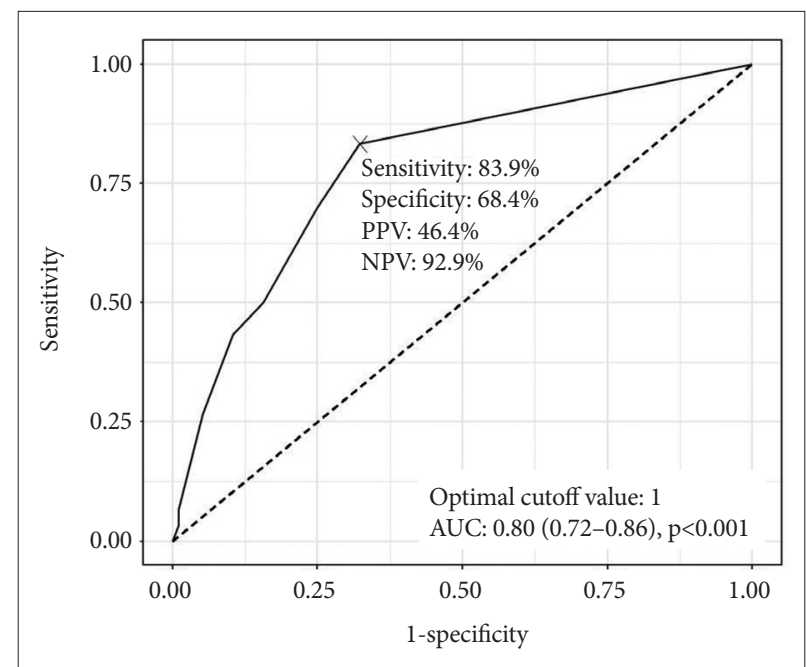

Supplementary Figure 1. Receiver operating characteristic curve of Psychosis Screener scores for predicting severe mental illness disorders including schizoaffective disorder, schizophrenia spectrum disorder (ICD-10 codes: F20-F29), affective psychosis such as bipolar disorder (F31), and recurrent depressive disorder (F33). PPV: positive predictive value, NPV: negative predictive value, AUC: area under the curve. 